\title{
TRASH-TO-GAS: Converting Space Trash into Useful Products
}

\author{
Anne J. Caraccio ${ }^{1}$ and Paul E. Hintze ${ }^{2}$ \\ National Aeronautics and Space Administration, Kennedy Space Center, Mail Stop NE-L6, Florida 32899
}

NASA's Logistical Reduction and Repurposing (LRR) project is a collaborative effort in which NASA is determined to reduce total logistical mass through reduction, reuse and recycling of various wastes and components of long duration space missions and habitats. LRR is focusing on four distinct advanced areas of study: Advanced Clothing System, Logistics-to-Living, Heat Melt Compactor and Trash to Supply Gas (TtSG). The objective of TtSG is to develop technologies that convert material waste, human waste and food waste into high-value products. High-value products include life support oxygen and water, rocket fuels, raw material production feedstocks, and other energy sources. There are multiple pathways for converting waste to products involving single or multi-step processes. This paper discusses thermal oxidation methods of converting waste to methane. Different wastes, including food, food packaging, Maximum Absorbent Garments (MAGs), human waste simulants, and cotton washcloths have been evaluated in a thermal degradation reactor under conditions promoting pyrolysis, gasification or incineration. The goal was to evaluate the degradation processes at varying temperatures and ramp cycles and to maximize production of desirable products and minimize high molecular weight hydrocarbon (tar) production. Catalytic cracking was also evaluated to minimize tar production. The quantities of $\mathrm{CO}_{2}, \mathrm{CO}, \mathrm{CH}_{4}$, and $\mathrm{H}_{2} \mathrm{O}$ were measured under the different thermal degradation conditions. The conversion efficiencies of these products were used to determine the best methods for producing desired products.

\section{Nomenclature}

$\begin{array}{ll}\text { Al } & =\text { Aluminum } \\ \text { ACS } & =\text { Advanced clothing system } \\ \text { AES } & =\text { Advanced Exploration Systems } \\ \text { atm } & =\text { Atmosphere, standard } \\ C H_{4} & =\text { Methane } \\ C O & =\text { Carbon monoxide } \\ C O & =\text { Carbon dioxide } \\ F P S & =\text { Food Packaging Simulant } \\ F T I R & =\text { Fourier transform infrared spectrometer } \\ G C / M S & =\text { Gas chromatography-mass spectrometer } \\ H M C & =\text { heat melt compactor } \\ H F W S & =\text { High fidelity waste simulant } \\ I S S & =\text { International Space Station } \\ I S R U & =\text { In-situ resource utilization } \\ K S C & =\text { Kennedy Space Center } \\ L R R & =\text { Logistics Reduction and Repurposing } \\ L E O & =\text { Low Earth Orbit } \\ L F W S & =\text { Low fidelity waste simulant } \\ L T L & =\text { logistics-to-living } \\ M A G & =\text { Maximum absorbency garment } \\ M F U & =\text { MAGs, fecal and urine waste simulant } \\ M F W S & =\text { Medium fidelity waste simulant }\end{array}$

\footnotetext{
${ }^{1}$ Chemical Engineer, Materials Science Division, Mail Stop NE-L6, and AIAA Member

${ }^{2}$ Ph.D. Chemist, Materials Science Division, Mail Stop NE-L6
} 


$\begin{array}{ll}N_{2} & =\text { Nitrogen } \\ N A S A & =\text { National Aeronautics and Space Administration } \\ O_{2} & =\text { Oxygen } \\ P E & =\text { Polyethylene } \\ P E T & =\text { Polyethylene terephthalate } \\ \text { slm } & =\text { standard liters per minute } \\ T t S G & =\text { Trash to Supply Gas }\end{array}$

\section{Introduction}

$\mathrm{W}$ ASTE treatment methods used on past Space Shuttle missions and current International Space Station (ISS) missions involve mission crew members storing waste materials until return vehicles either bring the material back to earth or burn it during atmosphere reentry. With the retirement of the Space Shuttle program and NASA's plans for long duration deep space missions beyond low earth orbit (LEO), return missions to earth will become less frequent, increasing the volume of trash stored on ISS and atmospheric burns of waste becoming more common. As NASA moves towards deep space missions outside of LEO, the focus of space travel must also shift to developing advanced exploration systems and in-situ resource utilization (ISRU) systems. ISRU is part of NASA's Human Exploration Destination System Roadmap with a purpose of developing technologies that enable the capability of self-sufficiency at locations beyond LEO and that eliminate the requirement to launch large amounts of mass for consumables and other items. ${ }^{1}$ During long duration space missions and space travel, large amounts of human biological food and other material wastes are produced. The stored waste can present sanitation issues and occupies space that could otherwise be used for mission activity. Trash processing into consumables will provide useful consumables and reduce waste accumulation during long transit time, and provide a trash management technique while at the destination. ${ }^{1}$ In addition, humanity undertaking deep space travel must keep in mind planetary protection efforts and preserve the natural habitat of celestial bodies as much as possible. If microbes and other wastes are released into space environments from human spaceflight, there is a possibility of rediscovering life from human waste. The LRR project views waste as a resource from which useful products can be derived.

The Trash to Supply Gas (TtSG) effort, part of the LRR project, supports the Advanced Exploration Systems (AES) program through pioneering innovative "reduce, reuse and recycle" approaches of future deep space missions. The main objectives of TtSG is to develop technologies that recycle material waste, human waste and food waste into high-value products for long duration space missions and habitats. High-value products include life support oxygen and water, rocket fuels, feedstocks for material production, and other energy sources. When these products are produced in situ, the mass of the Earth departure stage is reduced, which allows for more cargo capability during earth's launch or reduces cost of resources required to bring on a deep space mission. TtSG technologies will minimize the volume of waste that has to be stored and completely stabilize the waste.

TtSG is currently focused on the production of methane and involves multiple technologies being developed at different NASA centers. ${ }^{2}$ This paper will discuss KSC's thermal degradation reactor which investigated a series of space waste simulants and various temperature cycles and gas feed mixtures to understand their thermal processing behaviors. The combination of system parameters to maximize the production of carbon dioxide $\left(\mathrm{CO}_{2}\right)$ would be determined for future downstream implementation into a Sabatier reactor for conversion of $\mathrm{CO}_{2}$ into methane $\left(\mathrm{CH}_{4}\right)$ and water $\left(\mathrm{H}_{2} \mathrm{O}\right) . \mathrm{CH}_{4}$ is a useful fuel for propellants and alternative energy while water is valuable for environmental control and life support systems. The Sabatier reaction is displayed below. The thermal degradation reactor and Sabatier reactor are not currently connected. KSC is currently testing catalysts and gas separation techniques prior to integrating the two reactors.

$$
\mathrm{CO}_{2}+4 \mathrm{H}_{2} \rightarrow \mathrm{CH}_{4}+2 \mathrm{H}_{2} \mathrm{O}
$$

\section{Characterization of Waste}

Efforts were made to standardize waste simulants used for the TtSG task. The standardized waste simulants introduced three incrementing levels of processing challenges: low, medium and high fidelity waste simulants. As each level is studied, understanding and overcoming limitations assists in progressing the waste treatment technology development. The use of standardized waste simulants ensures that accurate comparisons can be made between each test run in the reactor as well as different waste technologies developed at other NASA centers. Waste simulants for the TtSG study were identified from waste characterization records of historical ISS and Space Shuttle missions. ${ }^{3}$ an internal LRR NASA study took data from the historic mission studies and modeled the amount of 


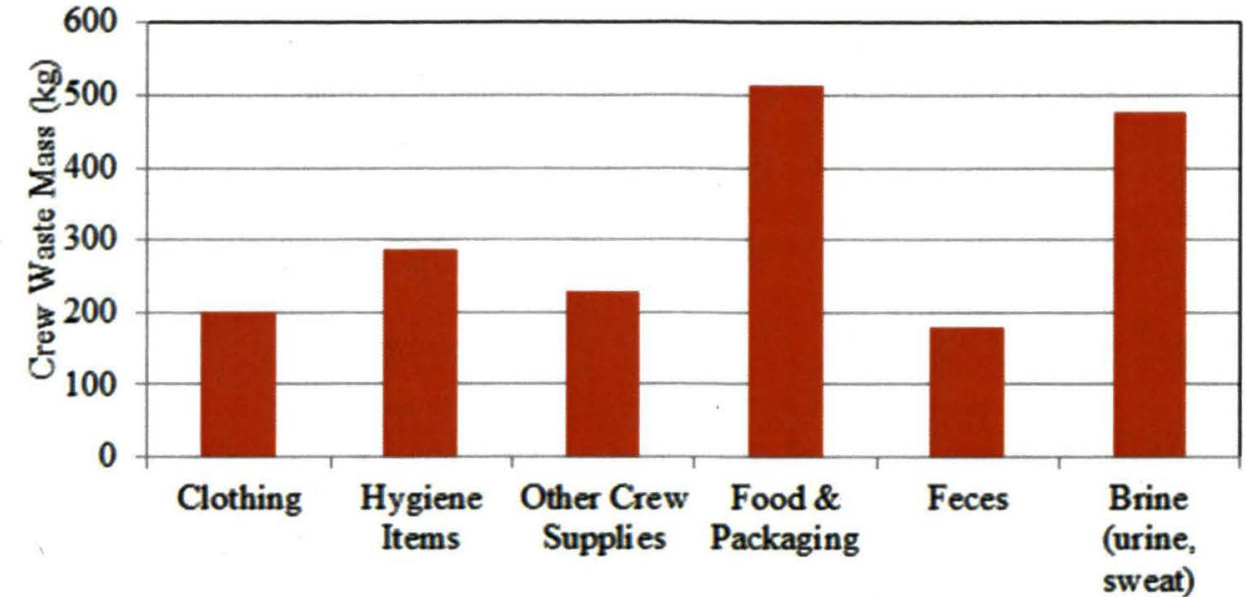

Figure 1. Current LRR crew waste model for a four-person crew on a one year mission waste generated from a four person crew on a one year space exploration mission. Figure 1 displays the major waste sources, such as clothing, hygiene items, crew supply, food and food packaging, feces and brine, generated during one year. These waste simulants may change in the future based on new waste models or mission requirements.

$\mathrm{KSC}$ investigated the

Table 1. High fidelity waste simulant recipe by mass weight percent.

\begin{tabular}{|l|l|}
\hline \multicolumn{1}{|c|}{ COMPONENT } & MASS $\%$ \\
\hline Cotton Towel & $17 \%$ \\
\hline Aluminum Foil & $5 \%$ \\
\hline FPS (PE, PET, Nylon) & $19 \%$ \\
\hline MFU (MAGs, Fecal, Urine) & $40 \%$ \\
\hline Food FOOD SIMULANT & $19 \%$ \\
\hline \multicolumn{2}{|c|}{} \\
\hline Juice & $41 \%$ \\
\hline Dried Apricot & $11 \%$ \\
\hline Tortilla & $21 \%$ \\
\hline Hot Dog & $27 \%$ \\
\hline \multicolumn{2}{|c|}{ FECAL SIMULANT } \\
\hline Cellulose & $6 \%$ \\
\hline Polyethylene glycol (PEG) & $3 \%$ \\
\hline Peanut Oil & $11 \%$ \\
\hline Miso & $17 \%$ \\
\hline Potassium chloride (KCl) & $2 \%$ \\
\hline Calcium chloride (CaCl2) & $1 \%$ \\
\hline Water & $60 \%$ \\
\hline
\end{tabular}

Table 2. Water Content of Waste Simulant

\begin{tabular}{|c|c|c|}
\hline CONTENT & DRY MASS $\%$ & ASH MASS $\%$ \\
\hline COTTON & $93.7 \%$ & $0.0 \%$ \\
\hline MAG & $92.4 \%$ & $11.8 \%$ \\
\hline FPS & $99.6 \%$ & $31.3 \%$ \\
\hline HFWS & $58.4 \%$ & $9.5 \%$ \\
\hline MFU & $29.5 \%$ & $4.3 \%$ \\
\hline
\end{tabular}
composition of the food packaging, which revealed that the food packaging was comprised of aluminum $(\mathrm{Al})$, polyethylene $(\mathrm{PE})$, and nylon and polyethylene terephthalate (PET). Eliminating brine and other crew supplies from this study, food packaging comprises over $40 \%$ of the waste by mass. Since PE consisted of more than half of food packaging mass, low fidelity waste simulant (LFWS) contained only PE for preliminary work with the reactor system. LFWS was used to understand the thermal degradation system before moving on to the more realistic and rigorous waste simulants. Only a short investigation was spent on the PE waste simulant, while more time was spent on the medium fidelity waste simulant (MFWS) and high fidelity waste simulant (HFWS) behavior. MFWS consisted of MAGs, FPS, and cotton towels. HFWS consisted of MFWS, fecal, urine and food waste simulant. When utilizing the trash reactor system in space, it is not intended for detailed trash separation prior to processing the waste. Trash simulant was loaded into the reactor in its natural mixed state to provide a realistic approach of processing the waste. MFWS accounts for approximately $50 \%$ total dry mass of waste produced in space, while the HFWS accounts for over $65 \%$ mass of waste generated. The percent by mass breakdown of the high fidelity, food and fecal waste simulant recipes are listed in Table 1. The waste simulants were cut into smaller segments before being placed into the reactor. The MAG, cotton washcloth and aluminum foil were cut into 1 inch squares and food simulant was mixed in a blender. The PE and nylon beads were approximately 0.0625 inches in diameter.

The water and ash content was determined for each of the waste simulants. The simulants were dried in crucibles at $110^{\circ} \mathrm{C}$ for 3 days. The dry samples were then heated to $575^{\circ} \mathrm{C}$ for 16 hours and the ash content was determined. The results of the water content of each waste simulant are displayed in Table 2 . Ash content was highest in the MAG and FPS. The fecal, food and urine simulant contained over $50 \%$ water, while the cotton, MAG and FPS contained over $90 \%$ dry mass. The dry mass was converted into carbon based products in the TtSG thermal degradation system. Water was collected in the condenser portion of the system and its weight recorded. 


\section{Experimental Set Up}

The thermal degradation reactor consisted of an Inconel tube reactor with a 1.5 inch internal diameter with an internal Watlow multi-cell tube heater. The waste simulant was pre-loaded into the reactor bed, which surrounded the tube heater. The heated zone of the reactor was approximately 9 inches tall with the tube heater at 8 inches tall. The void space of the reactor bed allowed $0.28 \mathrm{~L}$ of trash to surround a tube heater. This heated zone processed 10 grams of waste simulant per test.

Either air, nitrogen or a mixture of the two was fed into the bottom of the reactor while the reactor was being heated. Products leaving the top of the reactor traveled through a condenser, packed with steel beads and cooled with external thermal electric coolers (TECs) to chill the hot effluent reactor stream. A filter column, packed with glass wool, was placed downstream of the condenser to filter tar and collect other remaining solids of the stream prior to entering analysis instrumentation. The stream was then split and sent to a Fourier transform infrared spectrometer (FTIR) or a gas chromatograph-mass spectrometer (GC/MS) for analysis. Temperature and pressure readings were

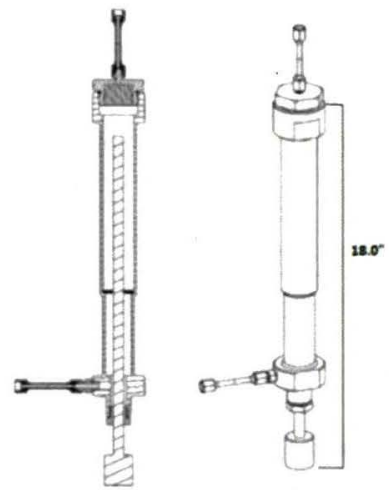

Figure 2. Thermal

Degradation Reactor controlled and acquired from integrated thermocouples and pressure transducers to Labview software which also recorded experimental data.

The FTIR was calibrated for quantifying $\mathrm{CO}_{2}, \mathrm{CO}$ and $\mathrm{CH}_{4}$ production and also identified $\mathrm{C}_{2} \mathrm{H}_{4}$ and long chain hydrocarbons for a comparative analysis. The GC/MS was able to identify the amount of oxygen in the exit stream. Both FTIR and GC/MS were able to qualitatively identify many hydrocarbons produced in the reaction. Heavy tars were collected in the condenser and filter, but were not subjected to analysis.

A large test matrix with variables of inlet flow rate, inlet gas composition, reactor temperature ramp rate, reactor temperature limit, waste simulant material and waste simulant mass was performed. The test matrix is shown in Table 3. These efforts allowed for testing of multiple parameters to understand how different waste simulants behaved at different thermal cycles in order to choose the best conditions to maximize the amount of $\mathrm{CO}_{2}$ production.

Table 3. Test Matrix

\begin{tabular}{|c|c|c|c|c|c|c|c|c|}
\hline \multirow[b]{2}{*}{$\begin{array}{c}\text { CASE } \\
\text { NUMBER }\end{array}$} & \multicolumn{2}{|c|}{ FLOW } & \multicolumn{2}{|c|}{ T CONDTIONS } & \multicolumn{2}{|c|}{ MATERIAL } & \multicolumn{2}{|c|}{ CATALYST } \\
\hline & $\begin{array}{l}\text { RATE } \\
\text { (SLM) }\end{array}$ & GAS & $\begin{array}{c}\text { RAMP } \\
{\left[{ }^{\circ} \mathrm{C} / \mathrm{MIN}\right]}\end{array}$ & $\begin{array}{c}\text { HOLD T } \\
{\left[{ }^{\circ} \mathrm{C}\right]}\end{array}$ & $\begin{array}{c}\text { WASTE } \\
\text { SIMULANT }\end{array}$ & $\begin{array}{c}\text { MASS } \\
{[\mathrm{g}]}\end{array}$ & $\begin{array}{c}\text { MASS } \\
\text { [g] }\end{array}$ & Type \\
\hline 1 & 5 & Air & 10 & 500 & HFWS & 10 & - & - \\
\hline 2 & 5 & Air & Full $(\sim 100)$ & 500 & HFWS & 10 & - & - \\
\hline 3 & 5 & Air & 10 & 100,500 & HFWS & 10 & - & - \\
\hline 4 & 5 & Air & Full $(\sim 100)$ & 500 & HFWS & 10 & 18 & Dolomag \\
\hline 5 & 5 & Air & 10 & 500 & Cotton Washcloth & 10 & - & - \\
\hline 6 & $2.5 \& 2.5$ & $\begin{array}{c}\text { Air \& } \\
\text { Nitrogen }\end{array}$ & 10 & 500 & Cotton Washcloth & 10 & - & - \\
\hline 7 & $2.5 \& 2.5$ & $\begin{array}{c}\text { Air \& } \\
\text { Nitrogen }\end{array}$ & 10 & 500 & FPS & 10 & - & - \\
\hline 8 & 5 & Air & 10 & 500 & FPS & 10 & - & - \\
\hline 9 & 5 & Air & 10 & 500 & FPS & 10 & - & - \\
\hline 10 & 5 & Air & 10 & 500 & MFU & 10 & - & - \\
\hline 11 & 5 & Air & 10 & 500 & MAG & 10 & - & - \\
\hline 12 & 2.5 and 2.5 & $\begin{array}{c}\text { Air \& } \\
\text { Nitrogen }\end{array}$ & 10 & 500 & MAG & 10 & - & - \\
\hline
\end{tabular}

\section{Results and Discussion}

Each case in the test matrix was performed in the thermal degradation reactor. The goal was to maximize the production of $\mathrm{CO}_{2}$ for downstream conversion to $\mathrm{CH}_{4}$ and liquid $\mathrm{H}_{2} \mathrm{O}$. The various combinations propagated many thermal degradation processes including pyrolysis, incineration and gasification.

\section{A. Minor Products}

As expected, the major products of the reactions included $\mathrm{CO}$ and $\mathrm{CO}_{2}$. Minor products included $\mathrm{CH}_{4}, \mathrm{H}_{2} \mathrm{O}$, $\mathrm{C}_{2} \mathrm{H}_{4}$, tar, and ash. Unconverted aluminum foil remained in the reactor after each experimental run. A list of 
Table 4. Trace byproducts and their classifications.

\begin{tabular}{|c|c|c|}
\hline CLASS NAME & PROPERTY & REPRESENTATIVE COMPOUNDS \\
\hline GC-Undetectable & Very heavy tars & \\
\hline ALKENE & Containing at least one carbon-to-carbon double bond & $\begin{array}{l}\text { Acetylene, Allene, 1-Butene, 1-Butene-3-yne, } \\
\text { Ethylene, Propene, 2-Methylpropene }\end{array}$ \\
\hline ALKANE & $\begin{array}{l}\text { Consist only of hydrogen and carbon atoms and are bonded } \\
\text { exclusively by single bonds }\end{array}$ & Ethane, Propane \\
\hline ALKYNE & $\begin{array}{l}\text { Hydrocarbons that have a triple bond between two carbon } \\
\text { atoms }\end{array}$ & Propyne, Ethyne \\
\hline ALDEHYDE & $\begin{array}{l}\mathrm{R}-\mathrm{CHO} \text {, consists of a carbonyl center (a carbon double } \\
\text { bonded to oxygen) bonded to hydrogen and an R group }\end{array}$ & Acetaldehyde, 2 propenal, \\
\hline CYCLOALKANE & One or more rings of carbon atoms & Methylenecyclopropane \\
\hline CYCLIC ETHER & $\begin{array}{l}\text { An oxygen atom connected to two alkyl or aryl groups - of } \\
\text { general formula } \mathrm{R}-\mathrm{O}-\mathrm{R}^{\prime}\end{array}$ & Ethylene Oxide \\
\hline DIENE & Contains two carbon double bonds. & 1,3-Butadiene \\
\hline KETONE & A carbonyl group $(C=0)$ bonded to two other carbon atoms & Acetone \\
\hline
\end{tabular}

byproducts identified in most runs is shown in Table 4. The effect of these small hydrocarbons on the overall trash to methane process is unclear. If trace amounts of these compounds are acceptable in a methane propellant, then they would pose no problem as long as they did not affect the Sabatier process. If either of these cases is a problem, they will need to be completely combusted or separated from the product stream.

Heavy tars were collected in the condenser and filter column. The tars were not analyzed, but they were present in all runs. Figure 3 shows a picture of the glass wool that has been discolored by tar. Tar and hydrocarbon byproducts may seriously limit the use of such technologies in closed systems of human spaceflight. Important efforts of tar and byproduct removal are important for the future capacity of converting trash into energy since a closed system in a space vehicle or habitat would not allow for any type of polluting mechanism with human life present. Current tar removal methods include modifying and controlling system conditions in order to achieve the desired composition of the product gas therefore eliminating tar byroduct. ${ }^{4}$ If perturbing the system to minimize tar

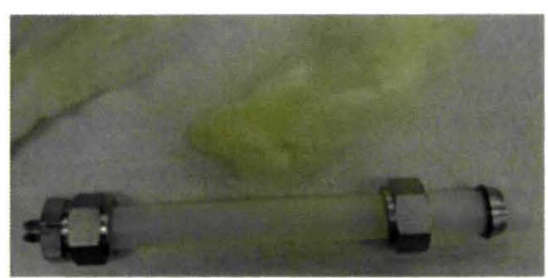

Figure 3. Glass wool, initially white, turned yellow from tar capture in the filter. production does not work, external measures such as scrubbers, catalytic cracking and other chemical conversion methods can be tested. The unreacted hydrocarbons will be reduced in future work through a modified second reactor manufactured at $\mathrm{KSC}$ as well as investigation of catalysis, which will also assist in cracking of long chain hydrocarbons.

Ash was also a minor product in the experimental runs, with approximately 0.85 grams left over from a 10 gram HFWS run. Some of the losses are not accounted for due to losses during transfer to weigh the amount. This accounts for roughly $8.5 \%$ ash accumulation from the trash, which matches closely with the measured ash percentage shown in Table 2.

\section{B. Variable Waste Simulant Experimentation}

It is important to describe the overall trends of the waste behavior that is presented in the FTIR and GC/MS analysis. The most commonly run test of the HFWS will be described here and the results of $\mathrm{CO}_{2}, \mathrm{CO}$ and $\mathrm{CH}_{4}$ are given in the data summaries. Air was fed to the reactor, which held 10 grams of pre-loaded simulant and was heated at a full ramp rate (approximately $100^{\circ} \mathrm{C}$ per minute) to $500^{\circ} \mathrm{C}$. When the reactor core temperature reached $500^{\circ} \mathrm{C}$, the external reactor wall temperature was approximately $300^{\circ} \mathrm{C}$ with the wall temperature still climbing over $400^{\circ} \mathrm{C}$ during the reaction time, nearly reaching the internal core heater temperature. Figure 4 displays the relationships described between the reactor core heater and the external wall temperature. Internal reactor temperature maintained a steady temperature rate due to the insulation installed externally on the reactor. Once the reactor core reached $500^{\circ} \mathrm{C}, \mathrm{CO}_{2}, \mathrm{CO}$ and $\mathrm{CH}_{4}$ compounds peaked in production rate. The production rates drastically reduced after 12 to 15 minutes.

The GC/MS detected a reduction in oxygen content from $21 \%$ to $11 \%$ for approximately 8 minutes during the $\mathrm{CO}_{2}$ peak production time. $\mathrm{CO}_{2}$ continued production for approximately 5 to 7 more minutes after the $\mathrm{O}_{2}$ levels returned to $21 \%$. The decrease in oxygen content from the GC/MS is displayed in Figure 5 . 


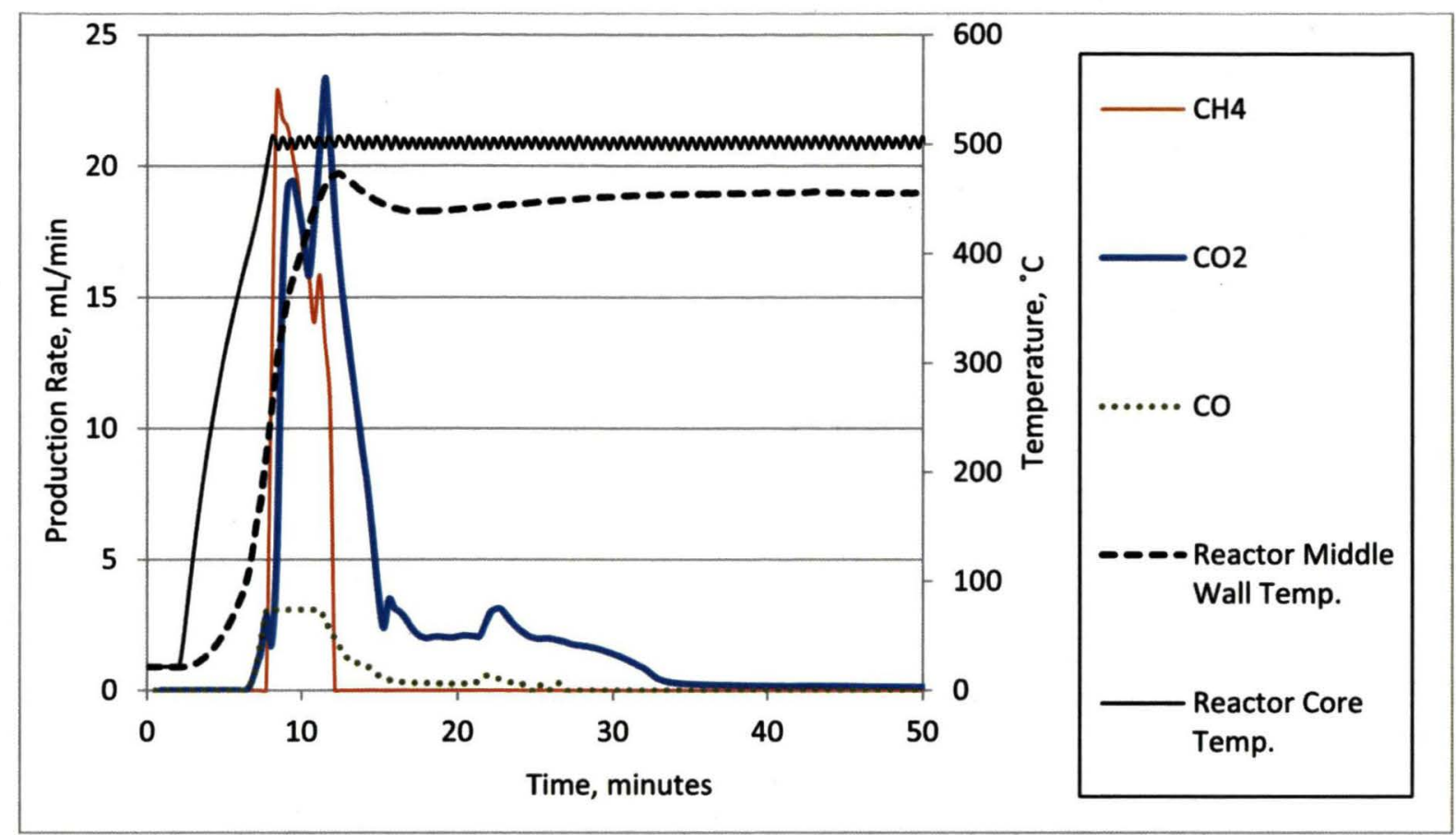

Figure 4. Production of $\mathrm{CO}, \mathrm{CH}_{1}$ and $\mathrm{CO}$ for a reactor containing HFWS.

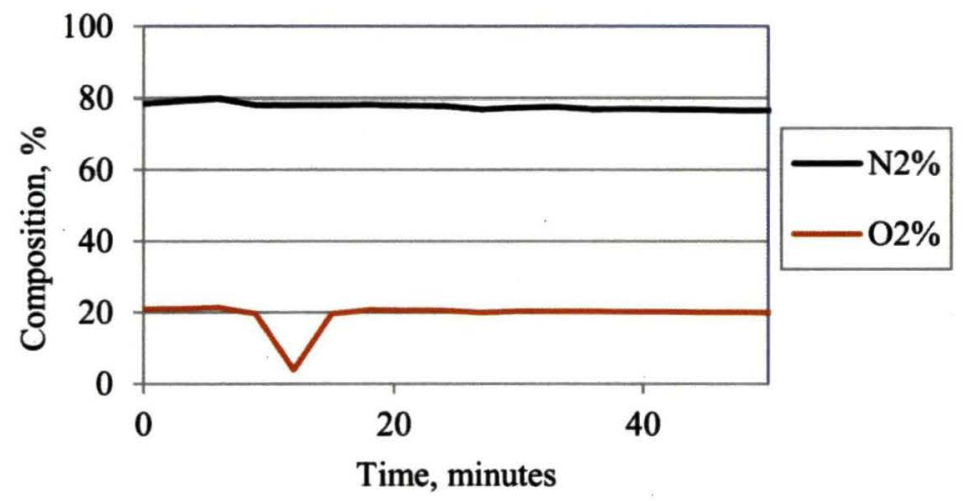

Figure 5. Decrease in $\mathrm{O}_{2}$ Content as Pyrolysis Dominates Reaction During $\mathrm{CO}_{2}$ Production

Each of the components making up the MFWS was tested as separate components to understand how the simulants behaved during thermal degradation before being combined into the HFWS. Figure 6 displays the production of $\mathrm{CO}, \mathrm{CO}_{2}$ and $\mathrm{CH}_{4}$ from several waste simulants of MFWS including cotton washcloths, FPS, MFU and MAGs.

The waste simulants produced over 6 grams of $\mathrm{CO}_{2}$ during the 10 to 15 minute production peak. The $\mathrm{CO}_{2}$ production from FPS with an air and nitrogen mixture is fairly low compared to the FPS with air. This is most likely due to the reduced oxygen content as nitrogen is introduced, favoring pyrolysis. The polymers may not have had enough oxygen to interact with, producing lower amounts of $\mathrm{CO}_{2}$, and more heavy tars. MFU simulant produced significantly less $\mathrm{CO}_{2}$ compared to the other MFWS which was due to the reduced amount of dry mass available for conversion. Only alkenes, alkanes and ketones were present in the byproducts for the MFU simulant as well. The longer chain byproducts were not as predominant in the MFU since PE, PET and Nylon were not present. MAGs contain some polymeric compounds like PE and polypropylene but mainly consist of pulp as fluff, which are typically small fibrous pieces of wood. ${ }^{5}$ Cotton washcloth is mainly composed of cellulose with the formula $\left(\mathrm{C}_{6} \mathrm{H}_{10} \mathrm{O}_{5}\right)_{n}$, which, in the right thermal conditions produced similar amounts of $\mathrm{CO}_{2}$ and $\mathrm{CO}$ in comparison to the FPS. 


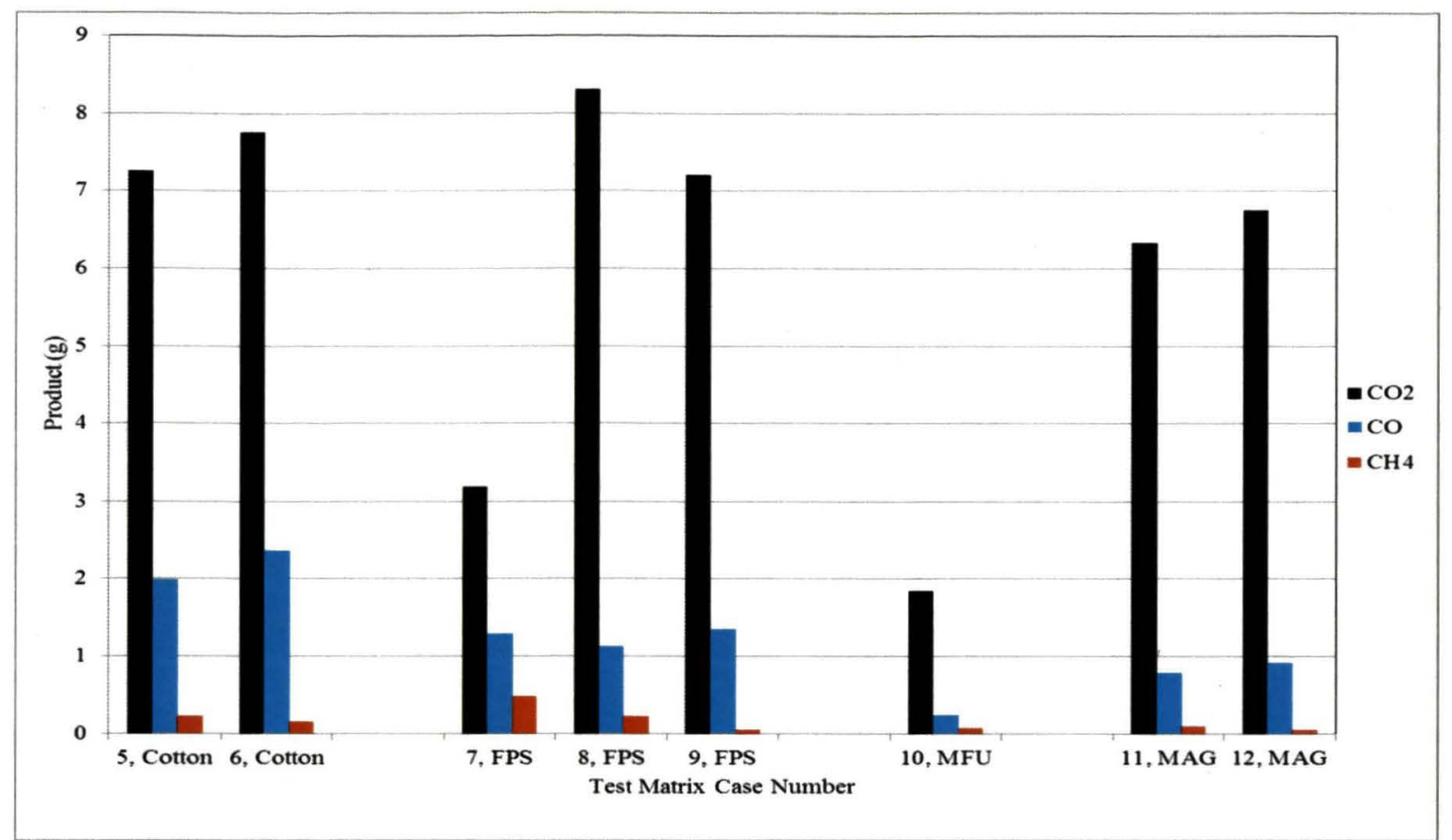

Figure 6. Degradation Products(in grams) of MFWS (based on Carbon basis)

HFWS results are displayed in Figure 7. When food and fecal matter were introduced into the HFWS system, lower averages of $\mathrm{CO}_{2}$ were produced. HFWS had a $\mathrm{CO}_{2}$ production range of 4.4 to 5.5 grams during the approximate 15 minutes of mean residence time in the reactor, while the MFWS had a range of 6.2 to 8.3 grams of $\mathrm{CO}_{2}$ with air fed systems. This was most likely a result of the high water content within the food, fecal and urine, decreasing the overall average dry mass to be converted into the desired product rather than condensed out of the system.

\section{Variable Gas Feed Experimentation}

Air at $5 \mathrm{slm}$, nitrogen $\left(\mathrm{N}_{2}\right)$ at $5 \mathrm{slm}$ and a mixture of air and $\mathrm{N}_{2}$ at $2.5 \mathrm{slm}$ each were fed to the reactor to observe behavior differences in $\mathrm{CO}_{2}$ production for different waste simulants. Pyrolysis dominated the system as pure nitrogen was fed to the reactor. Pyrolysis experiments were run with $5 \mathrm{slm}$ of $\mathrm{N}_{2}$ at a $10^{\circ} \mathrm{C}$ per minute ramp and held at $500^{\circ} \mathrm{C}$ with 10 grams of PE and repeated for 10 grams of MFWS. Both the PE and MFWS run with $\mathrm{N}_{2}$

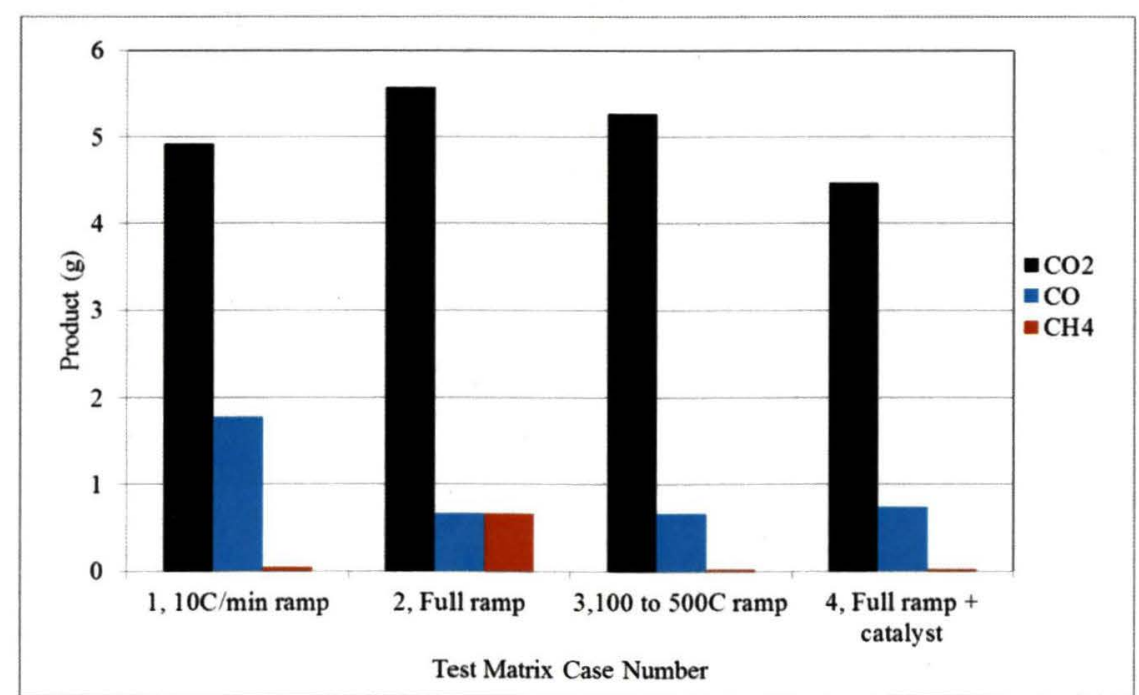

Figure 7. Degradation Products (in grams) of HFWS (based on Carbon produced less $\mathrm{CO}_{2}, \mathrm{CO}$ and $\mathrm{CH}_{4}$ compared to air or mixed gas experimental runs. Pyrolysis conditions caused many experimental issues including clogging and unreacted products and were eliminated early on in the testing phase.

For cotton and MAG simulants, the amounts of $\mathrm{CO}_{2}$ and $\mathrm{CO}$ were similar in air fed and air/nitrogen systems. The FPS produces twice as much $\mathrm{CO}_{2}$ in air than in the air/nitrogen fed mixture. Since there was no advantage to using the air and nitrogen mixture, pure air feeds were the focus for HFWS. 


\section{Catalyst Experimentation}

A dolomitic limestone catalyst, dolomag, was produced in a quarry from National Lime and Stone Company and shipped to KSC via Pioneer Astronautics. The dolomag was introduced into the HFWS to see if byproducts and tar production would be reduced and production of $\mathrm{CO}_{2}$ increased. Dolomag is mainly comprised of calcium carbonate. It was pre-loaded into the top of the reactor heated zone on top of the waste simulant. The dolomag catalyst did not support the same level of $\mathrm{CO}_{2}$ production compared to other HFWS testing as displayed in Figure 7. The dolomag did eliminate 2-propenal and allene byproducts from those listed in Table 5 of the GC/MS detection. The catalyst also collected black tar as displayed in Figure 8.

\section{E. Variable Heat Rate Experimentation}

Varying temperature heat cycles were studied to see if it affected the production of $\mathrm{CO}_{2}$. Three different heat cycles were chosen for the HFWS:

1. $10^{\circ} \mathrm{C}$ per minute ramp to $500^{\circ} \mathrm{C}$

2. Full ramp, approximately $100^{\circ} \mathrm{C} / \mathrm{min}$ to $500^{\circ} \mathrm{C}$

3. Partial ramp: $10^{\circ} \mathrm{C}$ per minute ramp to $100^{\circ} \mathrm{C}$, hold for 30 minutes, $10^{\circ} \mathrm{C}$ per minute ramp to $500^{\circ} \mathrm{C}$

The production of $\mathrm{CO}_{2}, \mathrm{CO}$ and $\mathrm{CH}_{4}$ are displayed in Figure 7 at the varying heat cycles. The highest production of $\mathrm{CO}_{2}$ occurred during a full ramp rate. Based on these results, future tests will heat the waste at maximum rate to the desired operating temperature. This is important for future implementation into a space system since the lowest possible power requirements are necessary as resources of power supply are limited in deep space travel. The maximum ramp cycle was the optimal selection when considering minimization of the power requirements for this test while retaining the efficiency of $\mathrm{CO}_{2}$ production.

\section{F. Production Rates}

The total production rates were calculated from the reactor data of the HFWS at the conditions of Label 2 in the Test Matrix. These production rates are based off of a 15 minute mean reaction time producing 0.3667 grams per minute of $\mathrm{CO}_{2}$, displayed in Table 5. This corresponds to processing approximately 1 kilogram of waste per day, or roughly 20 percent of the waste that is produced by a four person crew in one year. The production rates in the table are extended to show if the reactor ran continuously during periods of maximum $\mathrm{CO}_{2}$ production. These production rates were scaled up to processing 200 grams of trash to predict rates for the second generation TtSG reactor that is ten times large in volume. The current reactor is $0.28 \mathrm{~L}$ and can hold up to 20 grams of trash, producing approximately 192 kilograms per year of $\mathrm{CO}_{2}$ on a continuously run system. The $\mathrm{CO}_{2}$ from this reactor fed to a downstream Sabatier reactor would theoretically produce 70.13 kilograms per year of the desired product, $\mathrm{CH}_{4}$. When the system is scaled up, it should be able to process all waste and produce between 800 and $1,500 \mathrm{~kg}$ of $\mathrm{CH}_{4}$ per year, depending on the quantity of waste generated.

According to NASA's Exploration Systems Architecture Study estimates, approximately 4,000 kg per year of $\mathrm{O}_{2} / \mathrm{CH}_{4}$ (mixture ratio of 3.6:1 by mass) propellant is needed for an ascent stage of a Lunar Exploration Mission. ${ }^{6}$ This requires approximately 870 kilograms of $\mathrm{CH}_{4}$. Therefore, once the trash is converted to $\mathrm{CO}_{2}$ and fed to a downstream Sabatier reactor for $\mathrm{CH}_{4}$ production, scaled up production of this system should produce enough $\mathrm{CH}_{4}$ to fuel a lunar ascent vehicle.

\begin{tabular}{|c|c|c|c|}
\hline \multirow{2}{*}{ PRODUCTS } & $\begin{array}{c}\text { AIR FEED } \\
\text { (SLM) }\end{array}$ & $\begin{array}{c}\text { THERMAL DEGRADATION } \\
\text { REACTOR } \\
(\sim \mathbf{1 0 g} \text { trash) }\end{array}$ & $\begin{array}{c}\text { LARGE SCALE REACTOR } \\
\text { ESTIMATES } \\
(\sim 200 \mathrm{~g} \text { trash })\end{array}$ \\
\cline { 2 - 4 } & 5 & 192.74 & $\mathbf{k g} / \mathrm{yr}$ \\
\hline $\mathrm{CO}_{2}$ & 5 & 23.39 & $3,854.75$ \\
\hline $\mathrm{CO}$ & 5 & 70.13 & 467.78 \\
\hline $\begin{array}{c}\text { THEORETICAL } \\
\mathrm{CH}_{4}\end{array}$ & & $1,402.60$ \\
\hline
\end{tabular}

Table 5. Production Rates of First Generation TtSG Reactor 


\section{Conclusion}

There are many benefits from a trash processing system for deep space travel or habitats on other planets. Such a system reduces waste volume, and generates energy and life support commodities for deep space exploration systems and architectures. The TtSG system has many approaches for commodity production including integrated applications of ISRU for lunar or Mars missions, alternative energy systems (i.e. fuel cells), fuel for propulsion systems, $\mathrm{CO}_{2}$ for plant life support, ash production for activated carbon systems and water and oxygen for human life support. If certain commodities are produced during a space mission, this reduces the total logistical up mass that is needed to be sent from earth. This first generation TtSG reactor has successfully characterized reactor conditions for processing various waste simulants. The optimal HFWS reactor parameter was a full temperature ramp rate to $500^{\circ} \mathrm{C}$. These conditions could produce approximately 192 kilograms per year of $\mathrm{CO}_{2}$, if operating continuously, while reducing the trash mass by $20 \%$. Estimates of the Sabatier reactor to convert $\mathrm{CO}_{2}$ into $\mathrm{CH}_{4}$ yield a theoretical $\mathrm{CH}_{4}$ production rate of 70 kilograms per year. Scaling up by a factor of five from the current waste processing rate of $1 \mathrm{~kg} / \mathrm{day}$, would process all waste generated by a crew of four and generate between 800 and $1,500 \mathrm{~kg}$ of $\mathrm{CH}_{4}$ per year, depending on the quantity and composition of the waste. This is enough to fuel a lunar ascent stage vehicle, assuming the oxygen is generated by another ISRU process.

\section{References}

${ }^{1}$ Kennedy, Kriss J. Human Exploration Destination Systems Roadmap Technology Area 07. NASA. April 2010. http://www.nasa.gov/pdf/501327main_TA07-ID_rev7_NRC-wTASR.pdf.

${ }^{2}$ Hintze, P.E., Santiago-Maldonado- E., Kulis, M.J., Lytle, J.K., Fisher, J.W., Lee, J.M., Vaccaro, H., Ewert, M.K., and Broyan, J.L. Trash to Supply Gas (TtSG) Project Overview. AIAA Space 2012 Conference and Exposition, AIAA-2012-5254, AIAA, Pasadena, CA, 2012.

${ }^{3}$ Duffield, Bruce E., "Exploration Life Support Baseline Values and Assumptions Document. JSC-64367 Rev B." NASA Johson Space Center, Houston, Texas. February 26, 2010.

${ }^{4}$ Hlina, M. Plasma Gasification of Wood and Production of Gas with Low Content of Tar. Institute of Plasma Physics, ASCR, Czech Republic. May 2006.

${ }^{5}$ Hansen, Knud W., Wiertz, Pierra. Sustainability Report - Baby Diapers and Incontinence Products. The Absorbent Hygiene Products. Manufacturers Committee of EDANA. International Association Servince the Nonwovens and Related Inustries. EDANA. Brussels, Belgium. 2005. http://www.ahpma.co.uk/docs/Sustainability $\% 20$ Report $\% 20$ baby $\% 20$ diapers $\% 20$ and $\% 20$ incontinence $\% 20$ products.pdf

${ }^{6}$ Stanley, D., "NASA's Exploration Systems Architecture Study," NASA-TM-2005-214062. Washington, DC. NASA Headquarters, 2005 